\title{
MUNICIPALITIES AND HEALTH - CITIZENS' EXPECTATIONS ABOUT LOCAL HEALTH POLICIES
}

\section{Angelika S. Velkova, Paulina H. Kirova ${ }^{1}$}

Department of Social Medicine, Faculty of Public Health, Medical University - Sofia, Bulgaria

${ }^{1}$ Municipality of Pleven, Bulgaria

\author{
Corresponding Author: \\ Angelika S. Velkova \\ Dept. of Social Medicine \\ Faculty of Public Health \\ University Hospital "Tzaritza Ioanna" \\ 8 , Byalo more Str. \\ Sofia, 1527 \\ Bulgaria \\ e-mail:avelkova@abv.bg
}

Received: November 11, 2014

Revision received: September 16, 2015

Accepted: December 01, 2015

\section{Summary}

The aim of this study was to explore citizens' expectations about local health policies in order to create an adequate strategy. Local authorities in many countries place health in the core of their strategic planning aiming to create and improve a health-supporting social and physical environment, as they usually have primary responsibility for planning and/or delivering many of the services that are crucial to addressing the social determinants of health. Local health policies are created in consultation with local health services, NGOs and citizens. The survey was conducted among 400 citizens of Pleven Municipality. Of these, $335(83.75 \%)$ responded to the invitation. Information on health problems and determinants of health was collected through a direct inquiry survey. The majority of citizens considered the impact of environmental, educational, cultural and economic factors as well as public security on their health. They expected that more purposeful efforts of the local authorities be directed for improving living conditions and inequalities in health. The citizens are willing to work together with municipalities to create health policies, which reduce negative factors and increase positive ones. They are aware that local policies and decisions have a very significant impact on the economic, social and environmental factors affecting health and well-being and therefore municipalities play a key role in improving and protecting the health of their citizens.

Key words: health, municipality, well-being, health policy, citizens

\section{Introduction}

Health and wellbeing depend on many factors - such as personal characteristics, biological factors, individual skills of healthy life style, as well as environmental situation, social, cultural and economic conditions, availability, accessibility and quality of health care, social services, education, living and working conditions. Local authorities in many countries place health in the core of their strategic planning aiming to create and improve a health-supporting social and physical environment. Local governments define the rules and norms operating at the community. They manage the 
provision of public services and set the framework for long-term economic, social and environmental sustainability. Being a substantial part of state government systems, local governments provide an opportunity for the communities to make choices for themselves by adapting the actions of national government to the needs of the local population.

Local authorities in the Republic of Bulgaria have direct responsibility for public sectors with the greatest impact on health. They possess the greatest potential in the system of state power to improve the health and quality of life by integrating the joint efforts of citizens. Municipalities have the authority to accumulate and allocate public resources through which to model the conditions on their territory. Although the Health Act [1] does not regulate the competence of local authorities in the field of public health, practically about $80-90 \%$ of the budgetary expenditures of municipalities are focused on implementing policies that affect the determinants of health. As democratically elected authorities, Municipal Councils in Bulgaria have the right and responsibility to conduct local sectoral policies on municipal property, municipal enterprises, municipal finance, taxes, municipal administration; planning and development of the Municipality and the settlements in it. They take and implement decisions on local development of education, health, culture, social services, environmental protection and rational utilization of natural resources. Their powers include policies on maintenance and protection of the cultural, historical and architectural monuments, on development of sport, recreation and tourism, and addressing issues of local importance which do not fall within the exclusive competence of other public institutions [2].

Policy is among the most significant health determinants. It shapes the conditions in which people live and work, and these conditions can have positive or negative effects on individual and population health. Therefore Birley M. et al. stated that "It is obviously important to evaluate the effect of these influences on health." [3]. Health impact assessment (HIA) is a process by which the evidence (of different types), interests, values and opinions enter into a dialogue between stakeholders (politicians, professionals and citizens) so that they can imagine and anticipate the effects of changes in health and inequalities in health as a result of a specific proposal on a given population [4].
Participation of citizens and civil society organizations in the process of decision-making and policy making at a local level and the assessment of their impact on health is crucial for transparent and accountable local governance. In Recommendation № 19 (2001) of the Committee of Ministers for European citizen participation in local life it is explicitly stated that the dialogue between citizens and elected representatives in local government is essential for democracy, as it increases the legitimacy of local democratic institutions and their effectiveness [5].

The need for better utilization of evidence, information, research and analysis of all kinds to create and implement policies is widely recognized $[6,7,8]$. To our knowledge, the attitudes and expectations of citizens about the implementation of municipal health policy and their awareness of determinants of health have not been studied so far in Bulgaria.

The aim of this study was to examine the citizens' attitudes and expectations regarding establishment and implementation of municipal health policy as a basis for adoption and realization of appropriate solutions.

\section{Materials and Methods}

A survey was carried out among the residents of the Municipality of Pleven aged 17 to 84 years. The population of the Municipality was 121000 inhabitants, according to census data of the National Statistics Institute in 2011. We invited 400 citizens of Pleven and villages of Yasen, Koilovtsi, Bukovluk and Brestovets to participate in the study. Completed questionnaires were obtained from $335(83.75 \%)$ and the information was fully incorporated in the analysis. Random sampling was applied with the participation of several specific groups: workers aged 15-65 years, pensioners by age, unemployed, municipal councilors, citizens of Roma origin.

The study employed a direct inquiry method for collecting primary information. A questionnaire with 35 items was originally designed for the purpose of study. It was filled in by the respondents on the territory of enterprises, institutions, homes and clubs of the elderly. The average duration of filling in was 25 minutes.

We investigated the following major thematic areas:

- Impact of sectoral policies on community health: the citizens' assessment of the impact of environmental issues, education and 
municipal policies on culture, economic development, public order and security

- Expectations of citizens for implementing municipal policies on public health: how important is the Municipality to establish and fund programs in support of healthy life style and better access to medical care
- Attitudes towards civil participation in public health policy making on a local level.

Since the place of residence, age and education showed a significant influence on the respondents' answers we considered their effect on the results during the analyses. Distributions of study participants by some basic demographic and social characteristics are presented in Table 1.

Table 1. Demographic and social characteristics of study participants $(n=335)$

\begin{tabular}{|c|c|}
\hline Variable & Numbers and proportions (in \%) by category \\
\hline Sex & $\begin{array}{l}\text { - male }-150(45 \%) \\
\text { - female - } 185(55 \%)\end{array}$ \\
\hline Age & $\begin{array}{l}\text { - up to } 30 \text { yrs. }-59(17.6 \%) \\
\text { - } 31-45 \text { yrs. }-116(34.6 \%) \\
\text { - } 46-60 \text { yrs. }-105(31.3 \%) \\
\text { - over } 60 \text { yrs. }-55(16.4 \%)\end{array}$ \\
\hline Residence & $\begin{array}{l}\text { - urban }-236(70.4 \%) \\
\text { - rural - } 99(29.6 \%)\end{array}$ \\
\hline Economic activity status & $\begin{array}{l}\text { - public sector employed - } 125(37.3 \%) \\
\text { - private sector employed - } 104(31.0 \%) \\
\text { - entrepreneur - } 14(4.2 \%) \\
\text { - student - } 9(2.7 \%) \\
\text { - unemployed - } 27(8.1 \%) \\
\text { - retired - } 45(13.4 \%) \\
\text { - other - } 11(3.3 \%)\end{array}$ \\
\hline Education & $\begin{array}{l}\text { - less than primary }-3(0.9 \%) \\
\text { - primary - } 20(6 \%) \\
\text { - secondary/secondary vocational - } 190(56.7 \%) \\
\text { - higher }-122(36.4 \%)\end{array}$ \\
\hline Family status & $\begin{array}{l}\text { - married - } 210(62.7 \%) \\
\text { - single - } 70(20.9 \%) \\
\text { - single/divorced with children }-26(7.8 \%) \\
\text { - widowed with children }-29(8.7 \%)\end{array}$ \\
\hline
\end{tabular}

Data were processed with statistical software packages SPSS v. 19 and EXCEL for Windows. Classical statistical methods were applied in the analysis.

\section{Results}

\section{Impact of sectoral policies on community health}

In the first thematic area, citizens shared their views on the importance of assessing the health effects of municipal policy in several important sectors.

The majority of respondents - $270(80.6 \%)$ believed it was important that adoption of municipal sustainable development plans took into account their potential impact on public health. Only five $(1.5 \%)$ persons indicated that such assessment was not important at all.

The opinion of respondents differed significantly by place of residence $(p=0.001)$. Urban residents more often determined the assessment of effects on health as very important, while about a quarter of rural residents could not form an opinion and gave the answer "undecided" (Figure 1). 


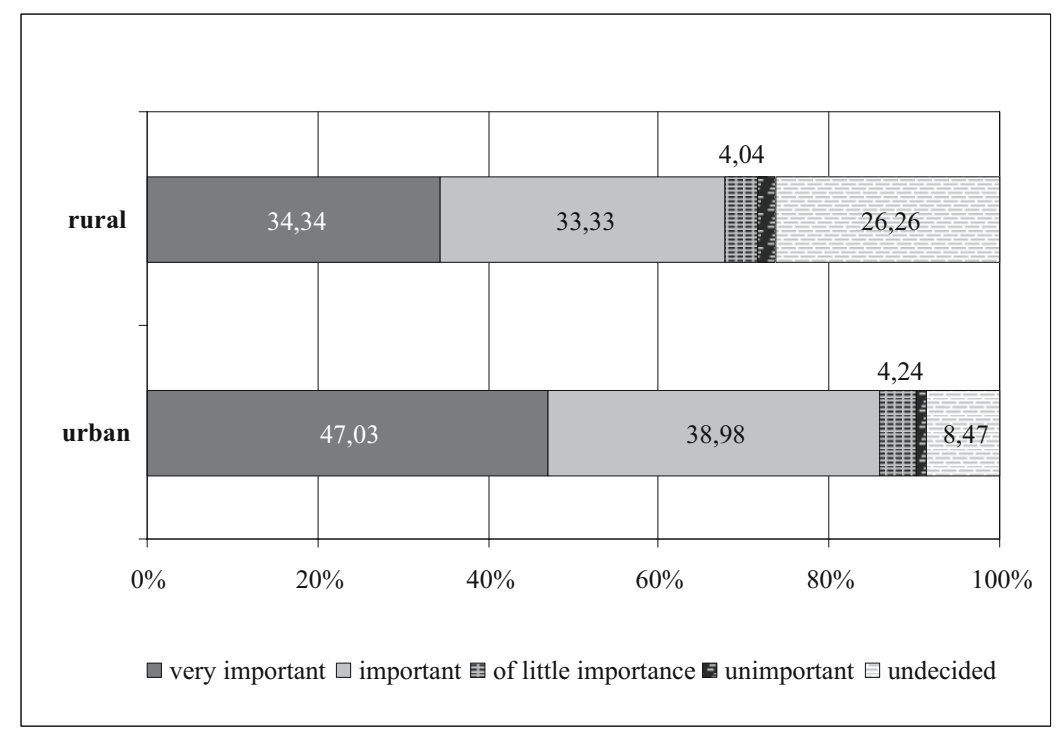

Figure 1. Assessment of the need to consider the effects on health when adopting Municipality development plan, depending on the place of residence

Citizens evaluated differently the need to consider the effect of specific sectoral policies on health. The assessment of environmental policies was most often described as important (Figure 2). Minor variation was observed in public opinion on the importance of assessing the health impact of policies for economic development, education, and public order and security. Culture and arts were not areas of social life that people associated with high health risk. Therefore a lower proportion of respondents - 216 (64.5\%), considered the evaluation of potential health effects of municipal policies in the cultural sector as important.

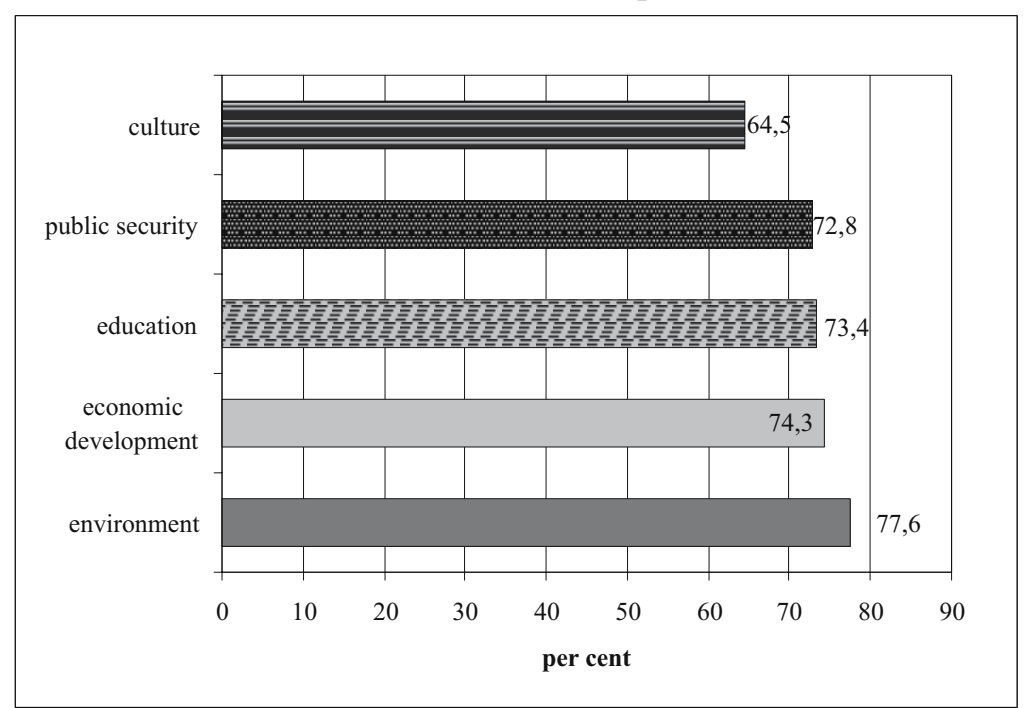

Figure 2. Ranking of the sectoral policies according to the importance of HIA

Respondents related the conditions of physical environment with the most significant opportunity to influence health. Almost $95 \%$ of them defined provision of safe and secure ecological environment as an undisputed priority of the Municipality. Only a small part - eight participants $(2.4 \%)$ were convinced that environmental protection was a responsibility solely of the central government.

The survey data revealed that $61(18.2 \%)$ of the respondents were interested in environmental situation of their location and actively sought updated information. In addition, $76(22.7 \%)$ of them felt being sufficiently informed about the 
issue. At the same time, the Municipal Program for Environmental Protection was well known to only $61(18.2 \%)$ of the citizens. More than half of the respondents - $196(58.5 \%)$ were slightly familiar with it, and $78(23 \%)$ were unaware of its existence.

The potential impact of environmental issues on health was assessed by $260(77.6 \%)$ of the respondents as important, and only $5(1.5 \%)$ stated that considering the effects on health in the process of formulation municipal environmental policy was not necessary. There were significant differences in the views of individuals depending on their age $(p<0.001)$, leaving the impression that young people under 30 more often stated no opinion on the effects of environmental policy (Figure 3).

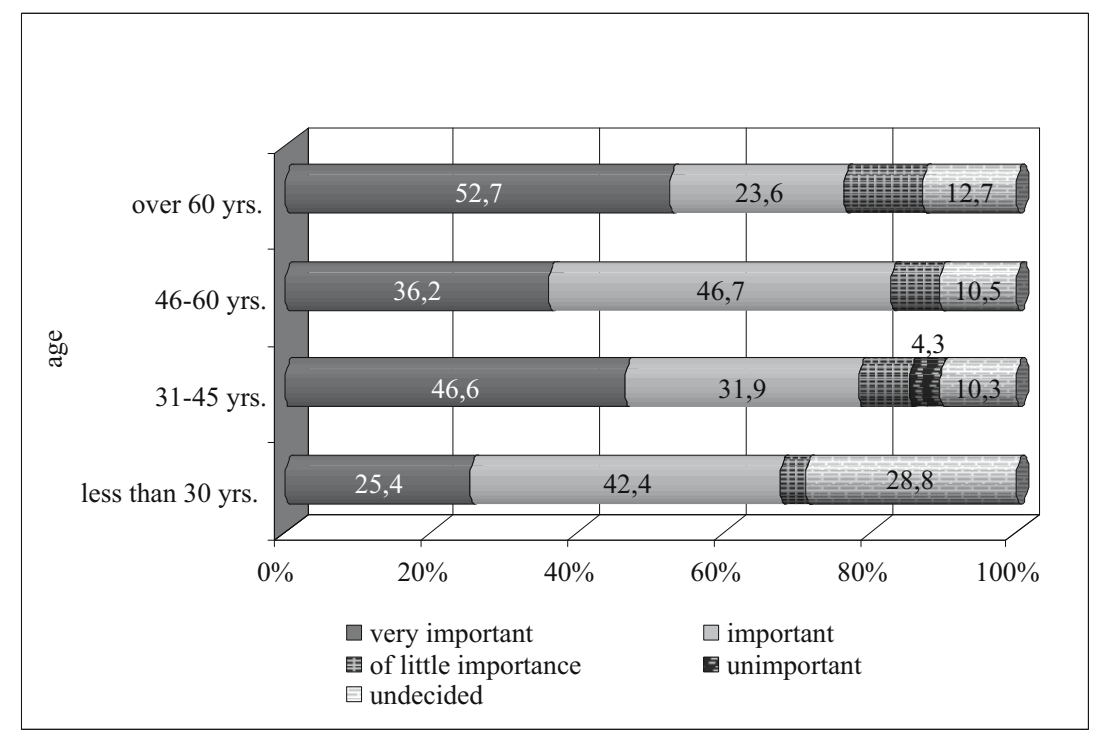

Figure 3. Assessment of considering the effects of environmental policies on health, depending on the age of the respondents

\section{Expectations of citizens for implementing municipal policies on public health \\ Healthy life style}

Policy formulation that meets the expectations of people in terms of health requires local politicians to be aware of citizens' attitudes regarding the factors of health and the opportunities for its improvement. In the present study, we examined the attitudes of citizens to the municipal programs supporting healthy life style by sport activities, preventing the use of psychoactive substances and strengthening adolescent health.

The majority of respondents (73.4\%) supported the idea that active sports engagements provide good health. Practicing sports requires the establishment of appropriate facilities and living environment to provide opportunities and support physical activity of people in towns and villages. About one third $(35.6 \%)$ of the respondents believed that the citizens of Pleven Municipality have very good or good opportunities to participate in sports. Completely opposite opinion was stated by $45(13.4 \%)$ of the respondents who claimed that citizens had no opportunity to play sports at all.

We found a significant difference $(\mathrm{p}=0,004)$ in the responses to this question, depending on participants' level of education (Figure 4). Almost two thirds of the people with university and college education gave negative answers on the opportunities for sports, while one-fifth of those with lower educational levels expressed no opinion.

Our study confirms a high public sensitivity to the problem of drug use. The vast majority of citizens - $305(91 \%)$, considered it to be among the most serious social problems. However, the activities of municipal centers for prevention of drug abuse were well familiar to only one-fifth of all respondents $(20.3 \%)$ and $116(34.6 \%)$ of them did not know about their existence.

Similar poor awareness of citizens was demonstrated on municipal programs for health 


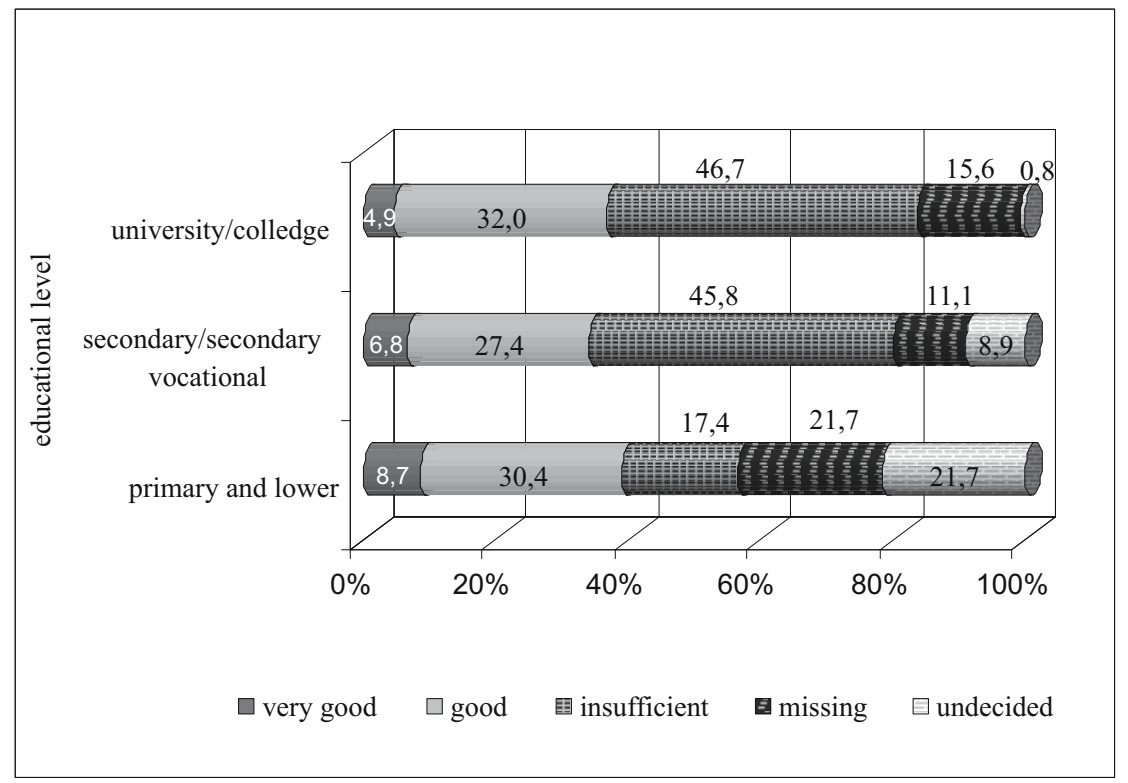

Figure 4. Assessment of opportunities for sports in the Municipality, depending on the education of the respondents

education of adolescents - only $52(15.6 \%)$ of the respondents were informed about them. Almost a half of the respondents - 179 (53.4\%) evaluated these programs as insufficient. A small proportion of the citizens' $-14.3 \%$ were well informed about the activities of school health offices and their prevention programs.

The respondents shared their views on preventive activities undertaken by the General Practitioners (GPs) working in the municipality. An insignificant proportion of citizens - 39 $(11.6 \%)$ considered the GPs' activities to strengthen health as sufficient. One in eight participants was not aware of preventive work in the primary care setting, and $79(23.6 \%)$ stated that GPs rarely performed preventive activities.

Nearly three quarters $(72.5 \%)$ of the respondents had little or no information about preventive activities undertaken by municipal health establishments. Only $92(27.5 \%)$ reported they were well and very well informed about these programs.

The majority of study participants $(85.4 \%)$ believed that it is important for the municipality to develop and fund programs in support of healthy life style. Only 5 respondents $(1.5 \%)$ assessed this public activity as unimportant at all.

\section{Accessibility to health services}

The study detected a significant gap between the current health needs of the municipality population and the provided health services. According to 153 (45.7\%) of the respondents, the provided health services did not meet the needs, and $148(44.1 \%)$ believed that the services were adequate in varying degrees to the existing health needs.

Exploration of public opinion on the accessibility of medical care revealed existing limitations in getting health services. The majority of people $-76.1 \%$ indicated that health services were inaccessible or insufficiently accessible to them, and only about one-fifth of the respondents $(21.2 \%)$ determined them as accessible.

We examined the citizens' opinion on the influence of two social factors (social status and ethnicity) on access to health services (Figure 5). Social status had strong and sufficiently strong influence on the accessibility to medical care, according to 253 (75.5\%) of the respondents. A small influence of the factor was determined by $48(14.3 \%)$ of them. One in ten respondents did not share any view on the effect of social status.

About half of the respondents (46.5\%) assessed the impact of ethnicity on the accessibility to health services as small. The effect of the factor was considered strong by 91 (27.1\%) of the respondents. Similar proportion of study participants $(26.3 \%)$ did not share their opinion on the influence of ethnicity. 


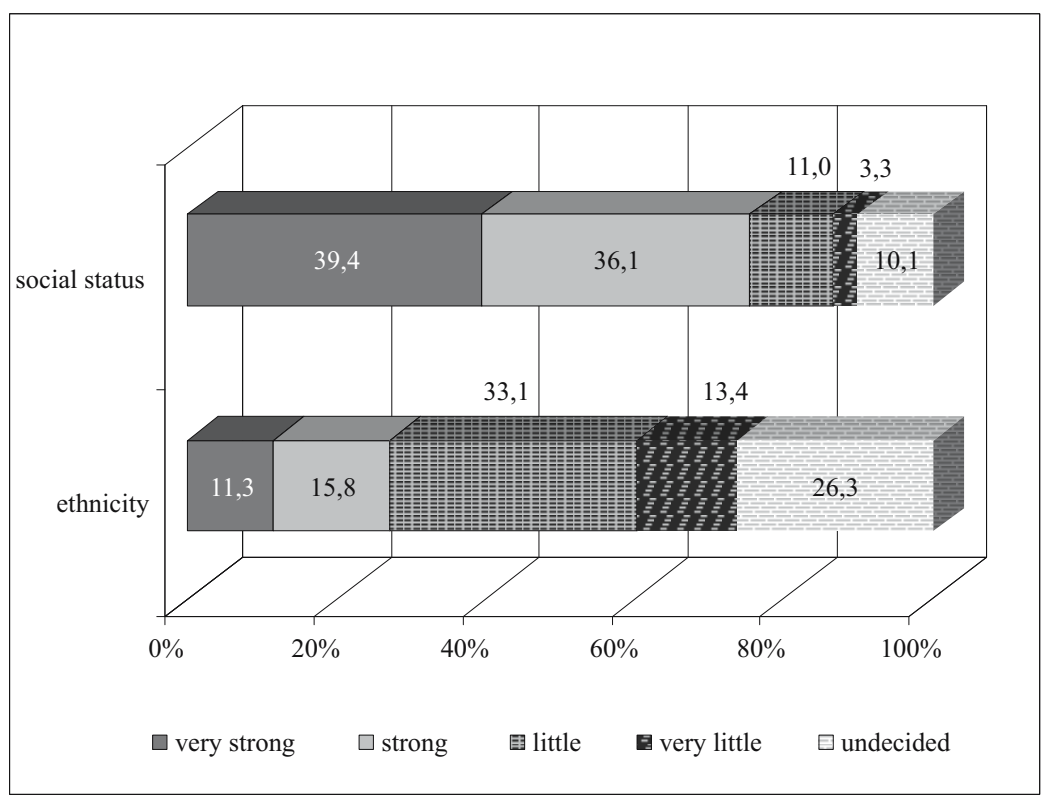

Figure 5. Effects of social status and ethnicity on the accessibility of health services

\section{Attitudes towards civil participation in public health policy-making at local level}

Explicit willingness to participate in public discussions on municipal health policy was expressed by $131(39.1 \%)$ of the respondents, and $132(39.4 \%)$ of them thought it was possible to take part. The age, place of residence and education did not affect the willingness of citizens to engage in the formulation of public health policies.

\section{Discussion}

Improving public health and addressing health inequalities at a local level in the municipalities are impossible without the active participation of people in the processes of decision-making and program implementation [9]. Participation of individuals, social groups and communities, together with public institutions, organizations and sectors in achieving better health and sustainable development are a core value and a guiding strategy for implementation of the program Health 21 in the European Region of WHO [10].

Effective public participation in the formulation and implementation of local development policies requires knowledge of attitudes and expectations of citizens to participate; of their assessments about community situation and community health; of impact of health determinants and effectiveness of current municipal policies and programs [11].

In our study we aimed to investigate the attitudes and expectations of citizens towards municipal policy, which takes into account the impact of sectoral policies on health, enables and supports healthy life style and encourages the participation of citizens.

We found out that the citizens were aware of the impact of environmental factors, education, security and economics on health and they accepted the need of assessing the impact of sectoral policies on community health. Respondents ranked the sectoral policies according to the importance of health impact assessment as follows:

- Environmental problems;

- Economic development;

- Public order and security;

- Education;

- Culture and arts.

The vast majority of respondents believed that the municipality had to develop and fund programs sustaining healthy life style. People were insufficiently informed or uninformed about health promotion activities of municipal health establishments and about the ongoing health education programs for adolescents.

Health services were of limited access to three-quarters of the respondents. According to the participants, accessibility of health services was strongly influenced by the social status. Most 
of the people were convinced that the Municipality had to finance fully or partially programs to improve the access of citizens to health services.

Citizens were willing to work together with local authorities in developing policies that reduce health risks of negative factors and increase benefits and well-being of the local community. They expected local authorities to play more active role in promotion and improvement of public health and decisive action to enhance local socio-economic situation and address inequalities in health.

We recommend that municipalities improve their interaction with public in the process of policy formulation by conducting systematic research of public opinion and involving people in different forms of direct participation in decision-making. The need of qualified local experts on health impact assessment and health policy has to be addressed in cooperation with medical universities in order to develop health policies relevant to current research and evidence.

\section{References}

Закон за здравето, обн. ДВ, бр.70 от 10.08.2004 г.

2 Закон за местното самоуправление и местната администрация, обн. ДВ, бр.77 от 17.09.1991 г.

1. Zakon za zdraveto, Darzhaven vestnik, No. 70 (August 10, 2004). Bulgarian.

2. Zakon za mestnoto samoupravlenie i mestnata administratsia, Darzhaven vestnik, No. 77 (September 17, 1991). Bulgarian.

3. Birley MH, Boland A, Davies L, Edwards RT, Glanville $\mathrm{H}$, Ison $\mathrm{E}$, et al. Health and environmental impact assessment: an integrated approach. London: Earthscan, British Medical Association; 1998.

4. World Health Organization Regional Office for Europe. Effectiveness of health impact assessment. Scope and limitations of supporting decision-making in Europe [Internet]. Copenhagen: World Health Organization, European Observatory on health system and policies; 2007 . Available from: http://www.euro.who.int

5. Council of Europe. Recommendation $\operatorname{Rec}(2001) 19$ of Committee of Ministers to Member States on the participation of citizens in local public life [Internet]. Available from: http://wcd.coe.int

6. Wyatt A. Evidence based policy making: The view from a centre. Public Policy and Administration. 2002;17(3):12-28.

7. Bullock H, Mountford J, Stanley R. Better policymaking. London: Centre for Management and Policy Studies; 2001.

8. Nutbeam D. How does evidence influence public healthy policy? Tackling health inequalities in England. Health promotion journal of Australia. 2003;14(3):154-8.

9. World Health Organization. European Sustainable Development and Health Series: 4. Community participation in local health and sustainable development. Approaches and techniques. World Health Organization; 2002.

10. World Health Organization. Health21: the health for all policy framework for the WHO European Region (European Health for All Series; No. 6). Copenhagen: WHO Regional Office for Europe; 1999 . A v a i l a b l e f r o m : http://www.euro.who.int/_data/assets/pdf_file/00 10/98398/wa540ga199heeng.pdf?ua=1

11. Hallsworth M, Parker S, Rutter J. Policy making in the real world. London: Institute for Government; 2011. 